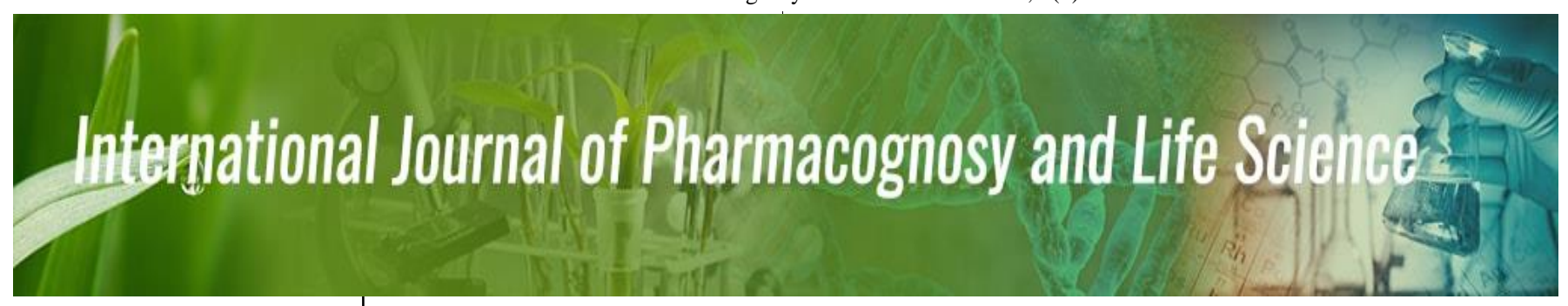

E-ISSN: 2707-2835 P-ISSN: 2707-2827 IJPLS 2020; 1(1): 38-41 Received: 21-11-2019 Accepted: 23-12-2019

Shakib Uzzaman Department of Pharmacy Varendra University Rajshahi, Bangladesh

\section{Pharmacological activities of neem (Azadirachta indica): A review}

\section{Shakib Uzzaman}

DOI: $\underline{\text { https://doi.org/10.33545/27072827.2020.v1.i1a.8 }}$

\begin{abstract}
Azadirachta indica, commonly known as neem, has attracted worldwide prominence in recent years, owing to its wide range of medicinal properties. Neem has been extensively used in Ayurveda, Unani and Homoeopathic medicine and has become a cynosure of modern medicine. Neem elaborates a vast array of biologically active compounds that are chemically diverse and structurally complex. More than 140 compounds have been isolated from different parts of neem. Neem possesses anti-diabetic, antioxidant, anti-viral, anti-inflammatory properties. Various effects like antibacterial, anti-fungal, anthelmintic, anti- parasitic, anticancer, anti HIV, antibone resorption, antispasmodic, antipyretic, antidiarrheal, immunomodulation, hypolipidemic, anti-microbial, hepatoprotective, gastro protective have also been studied.
\end{abstract}

Keywords: Neem, anticancer, antidiabetic, antimicrobial, antimalarial.

\section{Introduction}

Neem is a natural herb that comes from the neem tree, other names for which include Azadirachta indica and Indian lilac. The extract comes from the seeds of the tree and has many different traditional uses. Neem is known for its pesticidal and insecticidal properties, but people also use it in hair and dental products. All parts of the neem tree- leaves, flowers, seeds, fruits, roots and bark have been used traditionally for the treatment of inflammation, infections, fever, skin diseases and dental disorders. The medicinal utilities have been described especially for neem leaf. Neem leaf and its constituents have been demonstrated to exhibit immunomodulatory, anti-inflammatory, antihyperglycaemic, antiulcer, antimalarial, antifungal, antibacterial, antiviral, antioxidant, antimutagenic and anticarcinogenic properties. This review summarises the wide range of pharmacological activities of neem leaf.

\section{Synonyms of Azadirachat Indica}

- Azadirachta indica var. minor Valeton

- Azadirachta indica var. siamensis Valeton

- Azadirachta indica subsp. vartakii Kothari, Londhe \& N.P. Singh

- Melia azadirachta L.

- Melia indica (A. Juss.) Brandis

\section{Taxonomical Classification}

- Kingdom: Plantae

- Subkingdom: Tracheobionta

- Division: Magnoliophyta

- Class: Eudicot

- Subclass: Rosidae

- Order: Sapindales

- Family: Meliaceae

- Genus: Azadirachta

- Species: A. indica 


\section{Plant description}

Neem is a fast-growing tree that can reach a height of 15-20 metres (49-66 ft), and rarely 35-40 metres (115-131 ft). It is evergreen, but in severe drought it may shed most or nearly all of its leaves. The branches are wide and spreading. The fairly dense crown is roundish and may reach a diameter of 20-25 metres $(66-82 \mathrm{ft})$. The neem tree is very similar in appearance to its relative, the Chinaberry (Melia azedarach).

\section{Neem compound, Source \& Biological Activity}

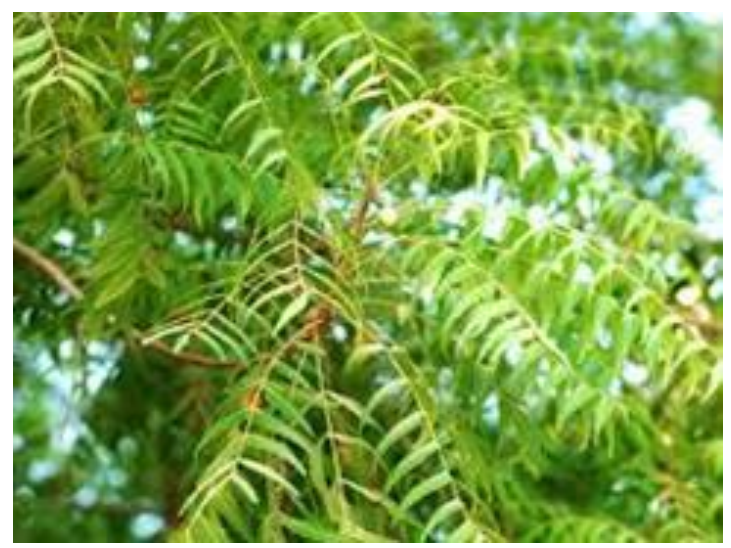

Fig: Neem Leaves
Various parts of the neem tree have been used as traditional Ayurvedic medicine in India. Neem oil and the bark and leaf extracts have been therapeutically used as folk medicine to control leprosy, intestinal helminthiasis, respiratory disorders, constipation and also as a general health promoter. Its use for the treatment of rheumatism, chronic syphilitic sores and indolent ulcer has also been evident. Neem oil finds use to control various skin infections. Bark, leaf, root, flower and fruit together cure blood morbidity, biliary afflictions, itching, skin ulcers, burning sensations and pthysis.

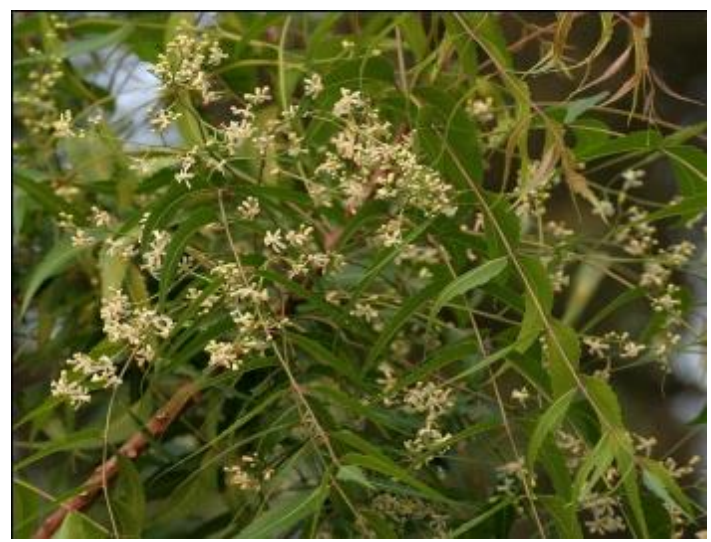

Fig: Neem buds and flowers

Table 1: Shows the Neem compound, Source \& Biological Activity

\begin{tabular}{|c|c|c|}
\hline Neem compound & Source & Biological activity \\
\hline Nimbidin & Seed oil & $\begin{array}{c}\text { Anti-inflammatory, Antiarthritic, Antipyretic, Hypoglycaemic, } \\
\text { Antigastric ulcer, Spermicidal Antifungal, Antibacterial, Diuretic. }\end{array}$ \\
\hline Sodium nimbidate & Anti-inflammatory. \\
\hline Nimbin & Seed oil & Spermicidal. \\
\hline Nimbolide & Seed oil & Antibacterial, Antimalarial \\
\hline Gedunin & Seed oil & Antifungal, Antimalarial \\
\hline Azadirachtin & Seed & Antimalarial \\
\hline Mahmoodin & Seed oil & Antibacterial. \\
\hline Gallic acid, (-) epicatechin and catechin & Bark & Anti-inflammatory, immunomodulatory. \\
\hline Margolone, margolonone and isomargolonone & Bark & Antibacterial \\
\hline Cyclic trisulphide and cyclic tetrasulphide & Leaf & Antifungal \\
\hline Polysaccharides & & Anti-inflammatory \\
\hline Polysaccharides GIa, GIb & Bark & Antitumour \\
\hline Polysaccharides GIIa, GIIIa & Bark & Anti-inflammatory \\
\hline NB-II peptidoglycan & Bark & Immunomodulatory \\
\hline
\end{tabular}

\section{Pharmacological uses}

\section{$>$ Antidiabetic}

The oral effective dose of $A$. indica leaf extract $(400 \mathrm{mg} / \mathrm{kg}$ body weight [b.wt]) was given once daily for 30 days to high-fat diet-induced diabetic rats. At the end of the experimental period, fasting blood glucose, oral glucose tolerance, serum lipid profile, and the levels of insulin signaling molecules, glycogen, glucose oxidation in gastrocnemius muscle were assessed

\section{$>$ Anti-inflammatory}

NSO in the dose of $0.25 \mathrm{ml} / \mathrm{kg}$ body weight did not show any significant anti-inflammatory activity. NSO showed increased inhibition of paw edema with the progressive increase in dose from $0.25 \mathrm{ml}$ to $2 \mathrm{ml} / \mathrm{kg}$ body weight. At the dose of $2 \mathrm{ml} / \mathrm{kg}$ body weight, NSO showed maximum $(53.14 \%)$ inhibition of edema at $4^{\text {th }}$ hour of carrageenan injection. Aspirin in the dose of $200 \mathrm{mg} / \mathrm{kg}$ body weight showed maximum inhibition of hind paw edema.
Conclusion: The present study concludes that NSO exhibits significant anti-inflammatory action.

\section{$>$ Hepatoprotective}

The aim of this study was to investigate the hepatoprotective role of azadirachtin-A in carbon tetrachloride (CCl4) induced hepatotoxicity in rats. The group allotment for the animals used in the hepatoprotective study included a vehicle treatment group, CCl4 $(1 \mathrm{~mL} \cdot(\mathrm{kg}$ body mass $)(-1))$ treatment group, silymarin $(100 \mu \mathrm{g} \cdot(\mathrm{kg}$ body mass $)(-1)$. day $(-1))+\mathrm{CCl} 4$ treatment group, and groups treated with different doses of azadirachtin-A (100 or $200 \mu \mathrm{g} \cdot(\mathrm{kg}$ body mass)(-1) - day(-1)) + CCl4. On the 9th day, blood was obtained for measuring the biochemical parameters, and liver tissue was obtained for pathological examination. The acute toxicity test with azadirachtin-A $(500,1000$, or 2000 $\mu \mathrm{g} \cdot(\mathrm{kg}$ body mass $)(-1)$ ) indicated no mortality after 14 days of treatment; further, there was no change in behavior, food 
consumption, or organ mass. However with the higher dose, some hematological parameters showed changes.

\section{Anti-hemorrhagic}

The minimum inhibitory concentration reached by $50 \%$ (MIC50) and 90\% (MIC90), and minimum bactericidal concentration for the extract were $2.5,>5$, and $10 \mathrm{mg} / \mathrm{ml}$, respectively. Neem extract showed antisecretory activity on Vibrio cholerae induced fluid secretion in mouse intestine with inhibition values of $27.7 \%, 41.1 \%, 43.3 \%, 57.0 \%$, and $77.9 \%$ at doses of $100,200,300,450$ and $1800 \mathrm{mg} / \mathrm{kg}$, respectively. Oral administration of the extract inhibited hemorrhage induced by Vibrio cholerae in mouse intestine at a dose $>$ or $=300 \mathrm{mg} / \mathrm{kg}$. The results obtained in this study give some scientific support to the uses of neem employed by the indigenous people in India employed for the treatment of diarrhea and dreadful disease cholera.

\section{$>$ Analgesic and Antipyretic}

The anti-inflammatory effect of aqueous extract of neem leaf (400 mg/kg body weight) was compared with that of dexamethasone $(0.75 \mathrm{mg}$, intraperitoneally $)$ by administering one hour before the formalin injection and once daily for 7 days in rats. The percentage of inhibition of paw edema in case of neem after 3, 6 hours, on day 3, 7 after formalin injection were $28,40,45,58 \%$ respectively and that in case of dexamethasone after 3, 6 hours, on day 3 , 7 after formalin injection were 43, 58, 61, 65\% respectively. The reduction was statistically significant in each case $(\mathrm{p}<0.001)$. The present study suggests that antiinflammatory effect of neem extract is less than that produced by dexamethasone.

\section{Kidney damage}

The results obtained in this study showed the aqueous crude extract of neem (A. indica) leaves exerted a dose-dependent protective activity of renal damage induced by P. berghei. It was most effective at the dose levels of 1,000 and $2,000 \mathrm{mg} / \mathrm{kg}$. This plant can be recommended for use since it possessed a high protective effect against malaria and can be obtained at relatively no cost from nature.

\section{$>$ Anti-ulcer}

The antiulcer effect of aqueous extracts of the leaves of the neem tree was investigated in rats exposed to 2-h coldrestraint stress or given ethanol orally for $1 \mathrm{~h}$. Extracts were administered in doses of 10 , 40, or $160 \mathrm{mg}$ leaf $/ \mathrm{kg}$ body weight, either as single- or five-dose pretreatment regimens. Neem dose-dependently reduced gastric ulcer severity in rats subjected to stress and also decreased ethanol provoked gastric mucosal damage.

\section{$>$ Antibone resorption}

Adult female Sprague-Dawley rats, weighing between 140$180 \mathrm{~g}$ were used. There were 3 main experimental groups. Group 1 rats received $1 \mathrm{~g} / \mathrm{kg}$ of alcoholic extract of Neem flower by gavage for 3 weeks and the effect on estrous cycle studied. Group 2 rats were administered $1 \mathrm{~g} / \mathrm{kg}$ of Neem flower alcoholic extract at 9 a.m. and at 6 p.m. on proestrus and the effect on the number of ova shed on the morning of estrus observed. Rats in Group 3 were treated with $1 \mathrm{~g} / \mathrm{kg}$ of alcoholic extract of Neem flower on days 1 to 5 postcoitum, and observation was made for anti-implantion / abortifacient effects and possible teratogenic effects on the foetuses. All the groups were control-matched.

\section{$>$ Antibacterial}

The neem NE at lower concentration $(0.7-1 \mathrm{mg} / \mathrm{mL})$ is found to be nontoxic while it is toxic at higher concentrations $(1.2-2 \mathrm{mg} / \mathrm{mL})$. The oxidative stress induced by the neem NE is evidenced by the depletion of catalase, SOD, and GSH levels in human lymphocytes. Neem NE showed a significant increase in DNA damage when compared to control in human lymphocytes $(P<0.05)$. The $\mathrm{NE}$ is an effective antibacterial agent against the bacterial pathogen $V$. vulnificus, and it was found to be nontoxic at lower concentrations to human lymphocytes.

\section{$>$ Antifungal}

Neem (Azadirachta indica) extract (NE) and NE combined with copper sulfate and boric acid (NECB) were examined for their protective effect against fungal deterioration of mango (Mangifera indica) and rain tree (Albizia saman) wood. Growth of the white-rot fungus Schizophyllum commune was completely inhibited on solid medium containing $1.8 \%(\mathrm{w} / \mathrm{w}) \mathrm{NE}$ or $5 \%(\mathrm{w} / \mathrm{w}) \mathrm{NECB}$. The average weight losses of NE and NECB treated wood blocks inoculated with $S$. commune were respectively $4.7 \%$ and $3.3 \%$ for $M$. indica and $4.1 \%$ and $3.0 \%$ for A. saman.

\section{$>$ Antiviral}

The antiviral and virucidal effect of methanolic extract fraction of leaves of neem (Azadirachta indica A. Juss) (NCL-11) was studied regarding its activity and possible mechanism of action against Coxsackie B group of viruses. NCL-11 inhibited plaque formation in 6 antigenic types of Coxsackie virus $\mathrm{B}$ at a concentration of 1000 micrograms/ml at $96 \mathrm{hrs}$. 'in vitro'. Additionally virus inactivation, yield reduction and effect of time of addition assays suggested that NCL-11 was most effective against coxsackie virus B-4 as a virucidal agent besides interfering at an early event of its replicative cycle. The evidence suggested that presence of a battery of compounds besides flavonoids, triterpenoids and their glycosides in NCL-11 have antiviral action for coxsackie $\mathrm{B}$ group of viruses 'in vitro.' The minimal inhibitory concentrations were not toxic to Vero (African green monkey kidney), cells; subtoxic concentration was $8,000 \mathrm{micrograms} / \mathrm{ml}$ and cytotoxic concentration 10,000 micrograms/ml, which was confirmed by trypan blue dye exclusion test.

\section{$>$ Immunoregulation}

The aqueous extract of neem bark and leaf also possesses anticomplement and immunostimulant activity. Neem oil has been shown to possess activity by selectively activating the cell-mediated immune mechanisms to elicit an enhanced response to subsequent mitogenic or antigenic challenge.

\section{Hyoglycaemic}

Aqueous extract of neem leaves significantly decreases blood sugar level and prevents adrenaline as well as glucose-induced hyperglycaemia. Recently, hypoglycaemic effect was observed with leaf extract and seed oil, in normal as well as alloxan-induced diabetic rabbits.

\section{$>$ Antioxidant activity}


The antioxidant activity of neem seed extract has been demonstrated in vivo during horse- grain germination.

\section{Effect on central nervous system}

Varying degrees of central nervous system (CNS) depressant activity in mice was observed with the leaf extract. Fractions of acetone extract of leaf showed significant CNS depressant activity.

\section{Conclusion}

Plants are one of the most important sources of medicines. The role of medicinal plants in promoting the ability of human health to cope with the unpleasant and difficult situations is well documented from ancient times till date all over the world. One of the cardinal goals of millennium development goals (MDGs) is the quest to combat the incidence of diseases such as malaria, HIV/AIDS and chronic diseases such as agerelated degenerative diseases, cancer and cardiovascular diseases. Medicinal plants are rich in secondary metabolites which are potential sources of drugs and of therapeutic importance. There is increasing interest in the use of plant extracts as therapeutic agents. Neem belongs to use pharmacological potential as panacea. From the literature survey it is found that mango is a potential source of anticancer, anti-diabetic, antiinflammatory, antimicrobial drugs as well as it also used as cardio protective, radio protective, recognition of memory and many others.

\section{Reference}

1. Almand B et al. Clinical significance of defective dendritic cell differentiation in cancer. Clin. Cancer Res. 2000; 6:1755-1766.

2. Gogati SS, Marathe AD. J Res. Educ. Indian Med. 1989; 8:1-5.

3. Aune TM, Collins PL, Chang S. Epigenetics and T helper 1 differentiation. Immunology. 2009; 126:299305.

4. Banchereau $\mathrm{J}$ et al. Harnessing human dendritic cell subsets to design novel vaccines. Ann. N. Y. Acad. Sci. 2009; 1174:24-32.

5. Banerjee DK, Dhodapkar MV, Matayeva E, Steinman RM, Dhodapkar KM. Expansion of FOXP3 high regulatory $\mathrm{T}$ cells by human dendritic cells (DCs) in vitro and after injection of cytokine-matured DCs in myeloma patients. Blood. 2006; 108:2655-2661.

6. Baral RN, Sarkar K, Mandal-Ghosh I, Bose A. Relevance of neem leaf glycoprotein as a new vaccine adjuvant for cancer immunotherapy, In Gupta V. K. (ed.), Research in bioactive natural products. Studium Press LLC, Houston, TX. 2010, 21-45.

7. Baral RN, Chattopadhyay U. Neem (Azadirachta indica) leaf mediated immune activation causes prophylactic growth inhibition of murine Ehrlich carcinoma and B16 melanoma. Int. Immunopharmacol. 2004; 4:355-366.

8. Badam L, Joshi SP, Bedekar SS. J. Commun. Dis., 1999; 31:79-90.

9. Balasenthil S, Arivazhagan S, Ramachandran CR, Nagini S. J. Ethnopharmacol. 1999; 67:189-195.

10. Blanco P, Palucka AK, Pascual V, Banchereau J. Dendritic cells and cytokines in human inflammatory and autoimmune diseases. Cytokine Growth Factor Rev. 2008; 19:41-52.
11. Bose A, Haque E, Baral R. Neem leaf preparation induces apoptosis of tumor cells by releasing cytotoxic cytokines from human peripheral blood mononuclear cells. Phytother. Res. 2007; 21:914-920.

12. Bose A. et al. Neem leaf glycoprotein induces perforin mediated tumor cell killing by $\mathrm{T}$ and $\mathrm{NK}$ cells through differential regulation of IFN $\gamma$ signaling. J. Immunother. 2009; 32:42-53.

13. Bose A. et al. Neem leaf glycoprotein directs T-bet associated Th1 type immune commitment. Hum. Immunol. 2009; 70:615.

14. Bose A, Baral RN. NK cellular cytotoxicity of tumor cells initiated by neem leaf preparation is associated with CD40CD40L mediated endogenous production of IL-12. Hum. Immunol. 2007; 68:823-831.

15. Corthay A. How do regulatory $\mathrm{T}$ cells work? Scand. J. Immunol. 2009; 70:326-336.

16. Chakraborty K, Bose A, Pal S, Chattopadhyay U, Baral R. Neem leaf glycoprotein restores the impaired chemotactic activity of peripheral blood mononuclear cells from head and neck squamous cell carcinoma patients by maintaining CXCR3/CXCL10 balance. Int. Immunopharmacol. 2008; 8:330-340.

17. Arivazhagan S, Balasenthil S, Nagini S. Phytother. Res., 2000; 14:291-293.

18. Chapuis F. et al. Differentiation of human dendritic cells from monocytes in vitro. Eur. J Immunol. 1997; 27:431-441.

19. Goswami S. et al. Neem leaf glycoprotein matures myeloid derived dendritic cells and optimizes anti-tumor $\mathrm{T}$ cell functions. Vaccine. 2010 28:1241-1252.

20. Bhanwra S, Singh J, Khosla P. Indian J Physiol. Pharmacol. 2000; 44:64-68.

21. Rao AD, Devi KN, Thyagaraju K. J Enzyme Inhib. 1998; 14:85-86.

22. Haque E, Mandal I, Pal S, Baral R. Prophylactic dose of neem (Azadirachta indica) leaf preparation restricting murine tumor growth is nontoxic, hematostimulatory and immunostimulatory. Immunopharmacol. Immunotoxicol. 2006; 28:33-50.

23. Baswa M, Rath CC, Dash SK, Mishra RK. Microbios. 2001; 105:183-189.

24. Rao AR, Kumar S, Paramsivam TB, Kamalakshi S, Parashuram AR, Shantha M. Indian J Med. Res. 1969; 57:495-502.

25. Arivazhagan S, Balasenthil S, Nagini S. Cell Biochem. Funct, 2000; 18:17-21. 